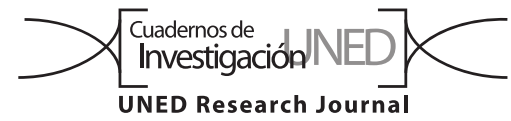

\title{
Efecto de agregar agua sobre el punto crioscópico y componentes de la leche cruda de vacas Jersey y Holstein
}

\author{
Rodolfo WingChing-Jones ${ }^{1}$ \& Esteban Mora Chaves ${ }^{2}$ \\ 1. Universidad de Costa Rica, Escuela de Zootecnia, Centro de Investigación en Nutrición Animal (CINA), Costa Rica; \\ rodolfo.wingching@ucr.ac.cr, (i) https://orcid.org/0000-0002-8009-2210 \\ 2. Unidad de Calidad de la Leche. Cooperativa Productores de Leche Dos Pinos R.L, Costa Rica; esmora@dospinos.com, \\ (D) https://orcid.org/0000-0002-7228-1767
}

Recibido 15-II-2019 • Corregido 22-IV-2019 • Aceptado 28-IV-2019

DOI: https://doi.org/10.22458/urj.v11i3.2609

\begin{abstract}
Effect of water addition on freezing point and components of raw milk from Jersey and Holstein cows". Introduction: The freezing point is used to assess the quality of raw whole milk and its byproducts. Objective: To determine the effect of water addition on freezing point, bromatological composition, urea content, somatic cell content and bacterial content in raw milk. Methods: During the first stage, we took 35 samples of milk $(80 \mathrm{~mL})$ from the towns of Turrialba in Cartago, and Zarcero in Alajuela (April and October 2018). We added water $(5,10,15,20,25$, and $30 \% \mathrm{w} / \mathrm{w})$ and kept an unadulterated sample as control (five repetitions each). Results: The addition of $5 \%$ water $(\mathrm{w} / \mathrm{w})$ was enough to alter all parameters. On a second stage, we tested lower concentrations (1, 2, 3, 4, and 5\% w/w). Conclusion: The addition of $1 \%$ water $(\mathrm{w} / \mathrm{w})$ produced significant changes only on three parameters: freezing point, bromatological contents, and somatic cell count.
\end{abstract}

Key words: Milk protein, milk solids, water adulterations, milk urea nitrogen, milk lactose, milk fat.
RESUMEN: Introducción: El punto crioscópico se usa para evaluar la calidad de la leche cruda entera y sus productos. Objetivo: Determinar el efecto de agregar agua sobre el punto crioscópico, composición bromatológica, contenido de urea, conteo de células somáticas y contenido de bacterias de la leche cruda. Métodos: Durante la primera etapa, tomamos 35 muestras de leche $(80 \mathrm{~mL})$ de las localidades de Turrialba en Cartago y Zarcero, en Alajuela (abril y octubre del 2018). Agregamos agua $(5,10,15,20,25$ y $30 \% \mathrm{p} / \mathrm{p})$ y una muestra sin adulterar como control (5 repeticiones de cada uno). Resultados: La adición de 5\% de agua $(\mathrm{p} / \mathrm{p})$ fue suficiente para alterar todos los parámetros. En una segunda etapa, evaluamos concentraciones más bajas (1, 2, 3, 4 y 5\% $\mathrm{p} / \mathrm{p})$. Conclusión: La adición de $1 \% \mathrm{p} / \mathrm{p}$ produce cambios significativos en tres parámetros: punto crioscópico, contenidos bromatológicos y conteo de células somáticas.

Palabras clave: Proteína en leche, sólidos totales, adulteración con agua, urea en leche, lactosa en leche, grasa en leche.
La leche cruda de vaca es valorada en la industria por sus características físicas, químicas y microbiológicas (WingChing-Jones \& Mora-Chaves, 2013). Está compuesta por agua, grasa, proteína, lactosa y minerales (Walstra, Wouters, \& Geurts, 2006). Estos componentes varían según el patrón racial de los animales (DePeters, Medrano, \& Reed, 1995), las condiciones climáticas en donde se desarrolla el sistema de producción (WingChingJones \& Mora-Chaves, 2015), el estado sanitario de la ubre (Alhussien \& Dang, 2018), el número de lactancia (Bohlouli, Alijani, \& Varposhti, 2015), el contenido de almidones (Gao \& Oba, 2016), el balance catión anión (Iwaniuk \& Erdman, 2015) y el contenido de proteína en la dieta (Sinclair, Garnsworthy, Mann, \& Sinclair, 2014); la edad del animal (Bohlouli et al., 2015), el estado de lactancia (Bohlouli et al., 2015) y los litros producidos al día (Feltes et al., 2016) entre otras variables.

En los sistemas donde el valor del litro de leche comercializado contempla estos componentes, es de importancia conocer los rangos de fluctuación de estos, control que permite al productor como al industrial detectar alteraciones que afecten la calidad de la leche. Alteraciones que podrían relacionarse a factores propios y de manejo del animal, como también a la adición de agua para aumentar el volumen de leche entregado; con azúcar, sal, bicarbonato de sodio, hidróxido de sodio, formaldehido o leche en polvo para incrementar la concentración de sólidos (Nascimento et al., 2017) o el mal funcionamiento del equipo de enfriamiento, el cual provoca que la leche se congele, se separen sus componentes, lo que afecta la calidad bromatológica. 
Dentro de los indicadores utilizados en los sistemas de industrialización de la leche para determinar alteraciones se cita el punto de congelación, índice de refracción, el peso específico y la conductividad eléctrica (Abernethy, Bendall, \& Holroyd, 2016). En el caso del punto crioscópico de la leche, corresponde a la temperatura en la cual la parte líquida y los solutos se encuentran en equilibrio, los valores normales de este indicador fluctúan entre $-0,510$ y $-0,530^{\circ} \mathrm{H}$, debido a que se encuentran en equilibrio con la presión osmótica de la sangre (Juárez-Barrientos et al., 2014). En el caso de Costa Rica, la Cooperativa de Productores de Leche Dos Pinos R.L., permite un rango de fluctuación del punto crioscópico de la leche entre $-0,525$ y $-0,560^{\circ} \mathrm{H}$ (Dos Pinos, 2016).

Este indicador varía según el país de origen, $-0,530^{\circ} \mathrm{H}$ en Checoslovaquia, $-0,505^{\circ} \mathrm{H}$ en Holanda, $-0,500^{\circ} \mathrm{H}$ Noruega, $0,515^{\circ} \mathrm{H}$ en Alemania, Austria y Suiza, y $-0,520^{\circ} \mathrm{H}$ en Dinamarca, Gran Bretaña, y Suiza (Hanuš et al., 2011). Según la raza del animal se encuentran valores de -0,516 para cruces entre Holsteins y Arshire, $-0,535$ para animales Holstein y -0,532 en animales Arshyre (Senevirathne, Mangalika, Adikari, \& Nayananjalie, 2016), -0,544 para animales Jersey, $-0,535$ animales Simental, $-0,536$ en Holstein rojo y $-0,537$ en Holstein negro (KedzierskaMatysek, Litwinczuk, Florek, \& Balowska, 2011). Por lo antes expuesto, el objetivo de esta propuesta fue el de determinar los cambios en el punto de congelación, la composición bromatológica de la leche, el contenido de urea, los conteos de células somáticas y contenido de bacterias de la leche cruda, relacionados a la adición de niveles crecientes de agua en muestras de leche provenientes de sistemas de producción de animales Holstein y Jersey.

\section{MATERIALES Y MÉTODOS}

Ubicación de los sistemas productivos: Las muestras se tomaron en las localidades de Turrialba, provincia de Cartago $\left(9^{\circ} 54^{\prime} 13,05^{\prime \prime} \mathrm{N}-83^{\circ} 40^{\prime} 09,02^{\prime \prime} \mathrm{O}\right)$ y en Zarcero, provincia de Alajuela Costa Rica $\left(10^{\circ} 11^{\prime} 47,18^{\prime \prime} \mathrm{N}\right.$ - $84^{\circ} 26^{\prime} 19,75^{\prime \prime} \mathrm{O}$ ), durante los meses de Abril y Octubre del año 2018. En la primera zona, se encontraba un hato de animales Jersey con un promedio de producción de $16 \mathrm{~L}$ animal/día, mientras que los semovientes de la raza Holstein presentaron un promedio de $25 \mathrm{~L}$ animal/día, se ubicaron en la segunda localidad. Ambos sistemas de producción se caracterizan por tener un pastoreo rotacional y una suplementación energética y proteica, que se ofrece en la canoa. Además, le entregan la totalidad de la producción a una cooperativa que agremia a la mayoría de los productores de leche en Costa Rica.
Toma de la muestra: En ambas etapas, se procedió a agitar por diez minutos el tanque de enfriamiento de la leche, el cuál contenía como mínimo dos ordeños completos. Pasado el tiempo de agitación, con ayuda de un recolector con capacidad de $20 \mathrm{~mL}$, se tomaron muestras de $80 \mathrm{~mL}$ de leche las cuales se colocaban en bolsas de plástico con cierre hermético con capacidad de $100 \mathrm{~mL}$.

Adulteración de la leche: En una primera etapa se trabajó con seis niveles de adulteración de la leche con adición de agua $(5,10,15,20,25$ y $30 \%$ p/p). Niveles que se determinaron por la suposición de que por error el agua contenida en la tina de lavado de las pezoneras fuera succionada y depositada en el tanque de enfriamiento. Cada nivel de adulteración fue repetido cinco veces, para un total de 30 bolsas de leche. Para comparar los resultados, se tomaron cinco muestras de leche, las cuales no se adulteraron. Estas 35 muestras, recolectadas en cada sistema productivo, fueron colocadas en una hielera con hielo y trasladas al laboratorio de calidad de leche de la Cooperativa de Productores de Leche Dos Pinos R.L., donde se analizó el porcentaje de grasa, proteína, lactosa y sólidos totales; el valor de urea en leche y el punto crioscópico. Para la caracterización bromatológica de la leche se procedió como lo indican WingChingJones y Mora-Chaves (2013) donde se utilizó $8 \mathrm{~mL}$ de leche para la determinación automática de las variables con ayuda del equipo MilkoScanTM FT 120 Type 71200 de FOSS Electric A/S. En el caso de la determinación de la urea en leche se utilizó el equipo ChemSpec 150 de Bentley Instruments y un kit a base de la enzima ureasa. En una segunda etapa y apoyados en los resultados obtenidos en la primera etapa, se pasó de rangos de adulteración de cinco unidades porcentuales a rangos unitarios, con niveles de adulteración de 0, 1, 2, 3, 4 y $5 \%$ de agua, para así determinar el mínimo porcentaje de agua adicionada que provoca en la leche entera un cambio significativo en su composición bromatológica (grasa, lactosa, sólidos totales), conteo bacterial y contenido de células somáticas, el valor de urea en leche y el punto crioscópico. Para alcanzar este objetivo, se tomaron cinco muestras de $80 \mathrm{~mL}$ de leche para cada nivel de adulteración en cada sistema de producción, para un total de 30 bolsas. De igual manera que en la primera etapa, las muestras fueron trasladadas en hielera con hielo, al Laboratorio de Calidad de Leche. El conteo de células somáticas se determinó mediante la metodología descrita para el equipo Fossomatic Serie 400 descrita por WingChing-Jones y Mora-Chaves (2013) donde se inyectan $10 \mathrm{ml}$ de leche cruda al equipo para el análisis. Para el conteo bacterial, se utilizó el equipo BactoCount IBC 50/ IBC 100 que por medio de la citometría de flujo 
realiza de forma automática el recuento de bacterias de forma individual (Bentley Instruments Inc). En este caso, se inyectan $6 \mathrm{ml}$ de la muestra de leche que es preparada con la adición de una solución buffer $(\mathrm{pH}=9,40)$, un colorante y reactivo de incubación específico del equipo. Mientras que el punto crioscópico fue determinado de forma automático con ayuda de un crióscopo (Modelo 4D3/4250-Advanced Instrumnets Inc), donde, 2,5ml de leche cruda presentan una disminución por debajo del punto de congelación hasta la cristalización, registrando la temperatura donde se da un balance entre la parte sólida y líquida de la muestra.

Análisis de la información: En ambas etapas, se utilizó un diseño irrestricto al azar para cuantificar el efecto de las adiciones crecientes de agua ( $p / p \%)$ sobre la concentración de grasa, proteína, lactosa, sólidos totales, el valor de punto crioscópico, contenido de urea en leche, conteo de células somáticas y conteo bacterial que presentó la leche cruda entera de animales Jersey y Holstein. Cuando se determinaron efectos significativos en cada variable dentro de una misma raza, se utilizó la prueba de Duncan $(p<0,05)$ para separar las medias de cada población. Además, se realizó una comparación entre razas según el comando PROC GLM de SAS, para determinar el efecto de raza sobre las variables bromatológicas de la leche, el contenido de urea y el punto crioscópico, para tal fin, se utilizaron las muestras de leche en cada raza que no fueron alteradas con agua.

Para determinar el porcentaje de cambio en cada componente de la leche cruda analizada en la primera y segunda etapa de esta investigación, se utilizó la siguiente ecuación para su determinación; el resultado obtenido se graficó de forma creciente según el porcentaje de adición de agua para cada componente bromatológico y de calidad de la leche analizado.

Porcentaje de cambio del componente $\mathrm{T}$ de la leche cruda $=[($ Valor del componente $X$ de la leche cruda Valor del componente $X$ de leche de cruda con $Y$ porcentaje de adición de agua) / Valor del componente $X$ en la leche cruda] $* 100$.

\section{Ética, conflicto de intereses y declaración de finan-} ciamiento: Los autores declaran haber cumplido con todos los requisitos éticos y legales pertinentes, tanto durante el estudio como en el manuscrito; que no hay conflictos de interés de ningún tipo, y que todas las fuentes financieras se detallan plena y claramente en la sección de agradecimientos. Asimismo, están de acuerdo con la versión editada final del documento. El respectivo documento legal firmado se encuentra en los archivos de la revista.

\section{RESULTADOS}

En la primera etapa del trabajo se demuestra que las muestras de leche provenientes de animales Jersey y Holstein en lactancia, varían significativamente $(p<0,05)$ la lectura del punto crioscópico, el porcentaje de grasa, proteína, lactosa, sólidos totales y el valor de urea en la leche, debida a la adición de 5\% de agua (p/p) (Cuadro 1). El punto crioscópico y componentes de la leche se nota una proporcionalidad en el porcentaje de cambio según el volumen de agua adicionada hasta un valor de 15\%, no así por encima de este porcentaje, donde el cambio en la respuesta no es proporcional (Fig. 1).

\section{CUADRO 1}

Cambios en el contenido de grasa, proteína, lactosa, sólidos totales, urea y punto crioscópico de la leche entera cruda de animales Jersey y Holstein debida a la adición creciente de agua (\%p/p).

\begin{tabular}{|c|c|c|c|c|c|c|c|c|c|c|c|c|c|c|}
\hline \multirow{3}{*}{ Tratamiento } & & \multirow{3}{*}{$\mathrm{N}^{\circ}$} & \multirow{2}{*}{\multicolumn{2}{|c|}{$\begin{array}{l}\text { Punto crioscópico } \\
\mathrm{m}^{\circ} \text { Horvert }^{*}\end{array}$}} & \multicolumn{8}{|c|}{ Porcentaje en leche } & \multirow{2}{*}{\multicolumn{2}{|c|}{$\begin{array}{c}\text { Urea en Leche } \\
\text { mg/dL }\end{array}$}} \\
\hline & & & & & \multicolumn{2}{|c|}{ Grasa } & \multicolumn{2}{|c|}{ Proteína } & \multicolumn{2}{|c|}{ Lactosa } & \multicolumn{2}{|c|}{ Sólidos totales } & & \\
\hline & & & Jersey & Holstein & Jersey & Holstein & Jersey & Holstein & Jersey & Holstein & Jersey & Holstein & Jersey & Holstein \\
\hline Sin adulterar & & 5 & $540,6^{a}$ & $539^{a}$ & $4,57^{\mathrm{a}}$ & $3,45^{\mathrm{a}}$ & $3,43^{\mathrm{a}}$ & $3,04^{a}$ & $4,71^{\mathrm{a}}$ & $4,72^{\mathrm{a}}$ & $13,34^{\mathrm{a}}$ & $11,84^{\mathrm{a}}$ & $11,67^{\mathrm{a}}$ & $15,73^{\mathrm{a}}$ \\
\hline \multirow[t]{6}{*}{ Adulterada ( $\mathrm{p} / \mathrm{p} \%$ ) } & 5 & 5 & $510,4^{b}$ & $508,4^{b}$ & $4,32^{b}$ & $3,26^{b}$ & $3,26^{\mathrm{b}}$ & $2,88^{b}$ & $4,51^{b}$ & $4,50^{b}$ & $12,67^{b}$ & $11,25^{b}$ & $9,87^{b}$ & $14,22^{\mathrm{b}}$ \\
\hline & 10 & 5 & $484,0^{c}$ & $480,2^{c}$ & $4,13^{c}$ & $3,10^{c}$ & $3,11^{c}$ & $2,74^{c}$ & $4,31^{c}$ & $4,29^{c}$ & $12,12^{c}$ & $10,72^{c}$ & $9,23^{c}$ & $13,14^{c}$ \\
\hline & 15 & 5 & $460,2^{d}$ & $458,2^{d}$ & $3,93^{d}$ & $2,97^{d}$ & $2,98^{d}$ & $2,62^{d}$ & $4,15^{d}$ & $4,12^{d}$ & $11,59^{d}$ & $10,27^{d}$ & $8,15^{d}$ & $12,29^{d}$ \\
\hline & 20 & 5 & $439,8^{e}$ & $435,8^{e}$ & $3,77^{e}$ & $2,83^{e}$ & $2,85^{e}$ & $2,50^{\mathrm{e}}$ & $3,98^{e}$ & $3,94^{e}$ & $11,10^{\mathrm{e}}$ & $9,81^{e}$ & $7,65^{d}$ & $11,14^{\mathrm{e}}$ \\
\hline & 25 & 5 & $420,0^{f}$ & $418,6^{f}$ & $3,60^{f}$ & $2,72^{f}$ & $2,74^{f}$ & $2,40^{f}$ & $3,83^{f}$ & $3,81^{f}$ & $10,67^{f}$ & $9,46^{f}$ & $6,63^{e}$ & $9,73^{f}$ \\
\hline & 30 & 5 & $403,0^{9}$ & $398,2^{9}$ & $3,49^{9}$ & $2,61^{\mathrm{g}}$ & $2,64^{9}$ & $2,31^{\mathrm{g}}$ & $3,70^{\mathrm{g}}$ & $3,67^{9}$ & $10,2^{9}$ & $9,09^{9}$ & $5,86^{f}$ & $9,41^{f}$ \\
\hline
\end{tabular}

*Letras diferentes en una misma columna para la raza Jersey, indican diferencias significativas entre medias según la prueba de Duncan $(p<0,05)$. 


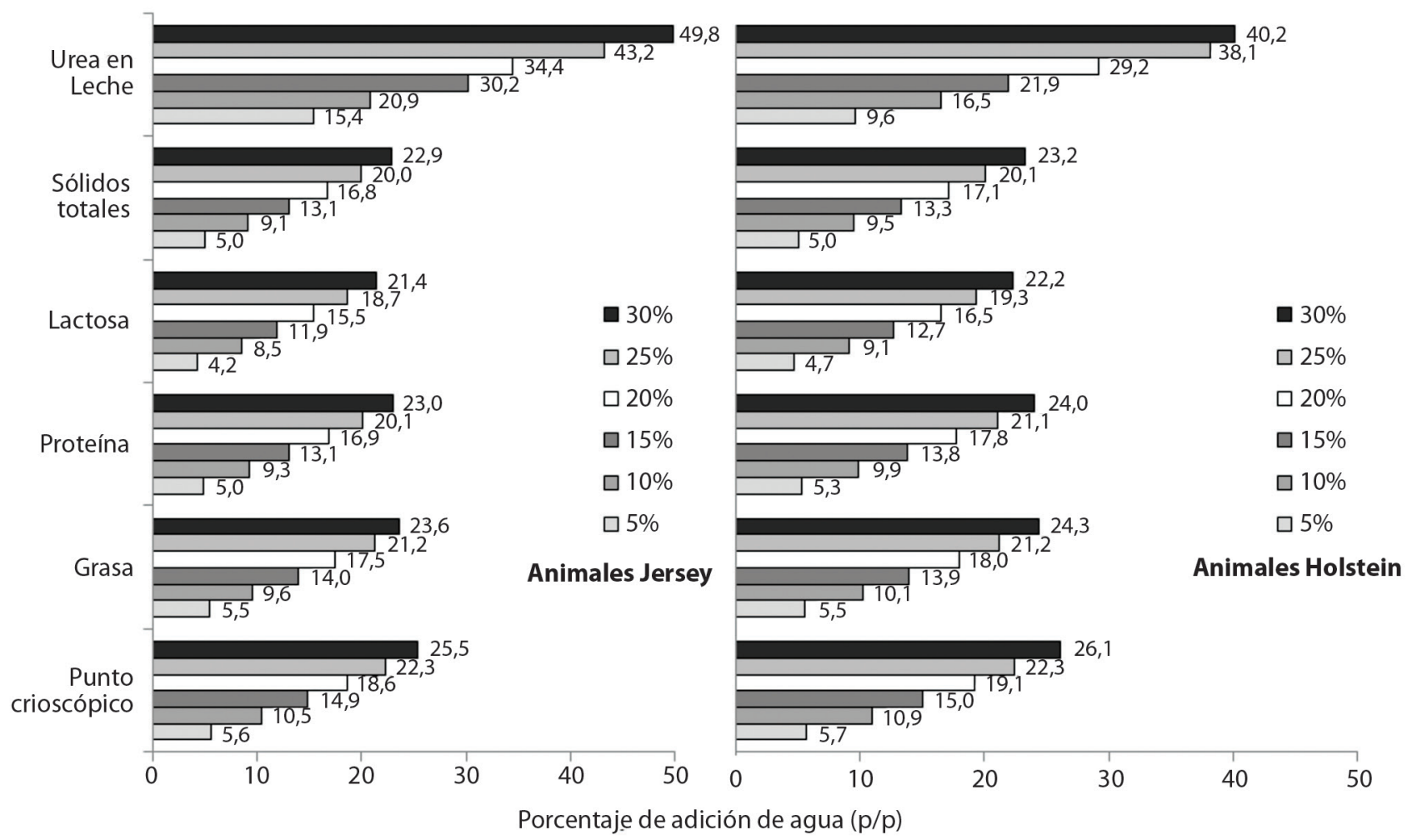

Fig. 1. Respuesta porcentual en los componentes de la leche cruda de animales Jersey y Holstein debidas a la adición creciente de agua hasta $30 \%(\mathrm{p} / \mathrm{p})$.

\section{CUADRO 2}

Cambios en el contenido de grasa, proteína, lactosa, sólidos totales, urea, células somáticas, unidades formadoras de colonia y punto crioscópico de la leche entera cruda de animales Jersey y Holstein debida a la adición de agua (\%p/p).

\begin{tabular}{|c|c|c|c|c|c|c|c|c|c|c|c|c|c|}
\hline \multirow{3}{*}{ Variables } & \multirow{3}{*}{ Unidades } & \multicolumn{12}{|c|}{ Leche entera cruda $\cdot$ Grado de adulteración con agua ( $p / p$ \%) } \\
\hline & & \multicolumn{2}{|c|}{ Sin adulterar } & \multicolumn{2}{|c|}{1} & \multicolumn{2}{|c|}{2} & \multicolumn{2}{|c|}{3} & \multicolumn{2}{|c|}{4} & \multicolumn{2}{|c|}{5} \\
\hline & & Jersey* & Holstein ${ }^{+}$ & Jersey & Holstein & Jersey & Holstein & Jersey & Holstein & Jersey & Holstein & Jersey & Holstein \\
\hline Punto crioscópico & $\mathrm{m}^{\circ}$ Horvert & $536^{\mathrm{a}}$ & $552^{\mathrm{A}}$ & $530^{\mathrm{b}}$ & $545^{\mathrm{B}}$ & $521^{c}$ & $540^{c}$ & $518^{c}$ & $532^{\mathrm{D}}$ & $513^{d}$ & $524^{\mathrm{E}}$ & $506^{e}$ & $519^{\mathrm{F}}$ \\
\hline Grasa & Porcentaje en & $4,4^{\mathrm{a}}$ & $3,7^{\mathrm{A}}$ & $4,3^{\mathrm{ab}}$ & $3,7^{\mathrm{B}}$ & $4,3^{b c}$ & $3,7^{c}$ & $4,2^{d c}$ & $3,6^{\mathrm{D}}$ & $4,2^{d}$ & $3,6^{\mathrm{E}}$ & $4,1^{e}$ & $3,5^{\mathrm{F}}$ \\
\hline Proteína & leche & $3,3^{\mathrm{a}}$ & $3,0^{A}$ & $3,2^{b}$ & $2,9^{\mathrm{B}}$ & $3,2^{c}$ & $2,9^{c}$ & $3,2^{c}$ & $2,9^{\mathrm{D}}$ & $3,2^{\mathrm{d}}$ & $2,8^{\mathrm{E}}$ & $3,1^{\mathrm{e}}$ & $2,8^{\mathrm{F}}$ \\
\hline Lactosa & & $4,3^{\mathrm{a}}$ & $4,7^{A}$ & $4,3^{b}$ & $4,7^{\mathrm{B}}$ & $4,2^{c}$ & $4,7^{c}$ & $4,2^{c}$ & $4,6^{D}$ & $4,2^{d}$ & $4,6^{\mathrm{E}}$ & $4,5^{e}$ & $4,5^{\mathrm{F}}$ \\
\hline Sólidos totales & & $12,9^{\mathrm{a}}$ & $12,2^{\mathrm{A}}$ & $12,8^{\mathrm{b}}$ & $12,0^{\mathrm{B}}$ & $12,6^{c}$ & $11,9^{c}$ & $12,5^{c}$ & $11,8^{\mathrm{D}}$ & $12,4^{d}$ & $11,6^{\mathrm{E}}$ & $12,9^{\mathrm{e}}$ & $11,5^{\mathrm{F}}$ \\
\hline Urea en leche & $\mathrm{mg} / \mathrm{dL}$ & $11,4^{\mathrm{a}}$ & $13,0^{A}$ & $10,7^{\mathrm{ab}}$ & $12,7^{\mathrm{AB}}$ & $10,8^{\mathrm{ab}}$ & $12,9^{A B}$ & $10,8^{\mathrm{ab}}$ & $12,9^{A B}$ & $10,4^{b}$ & $11,9^{c}$ & $10,4^{b}$ & $12,4^{\mathrm{BC}}$ \\
\hline $\begin{array}{l}\text { Conteo de células } \\
\text { somáticas }\end{array}$ & $\begin{array}{l}\text { células } / \mathrm{ml} \\
(\mathrm{x} 1.000)\end{array}$ & $412^{\mathrm{a}}$ & 128 & $404^{\mathrm{ab}}$ & 126 & $394^{\mathrm{ab}}$ & 127 & $397^{\mathrm{ab}}$ & 121 & $394^{\mathrm{ab}}$ & 119 & $387^{b}$ & 124 \\
\hline Recuento bacterial & $\begin{array}{l}\text { UFC/ml } \\
(x 1.000)\end{array}$ & 6 & $2,2^{c}$ & 5 & $3,4^{\mathrm{B}}$ & 6 & $4,8^{A}$ & 4,75 & $4,8^{A}$ & 5 & $5,2^{\mathrm{A}}$ & 4,4 & $4,6^{\mathrm{AB}}$ \\
\hline
\end{tabular}

*Letras minúsculas diferentes en una misma fila para la raza Jersey, indican diferencias significativas entre medias según la prueba de Duncan $(\mathrm{p}<0,05)$.

+ Letras mayúsculas diferentes en una misma fila para la raza Holstein, indican diferencias significativas entre medias según la prueba de Duncan $(p<0,05)$. 


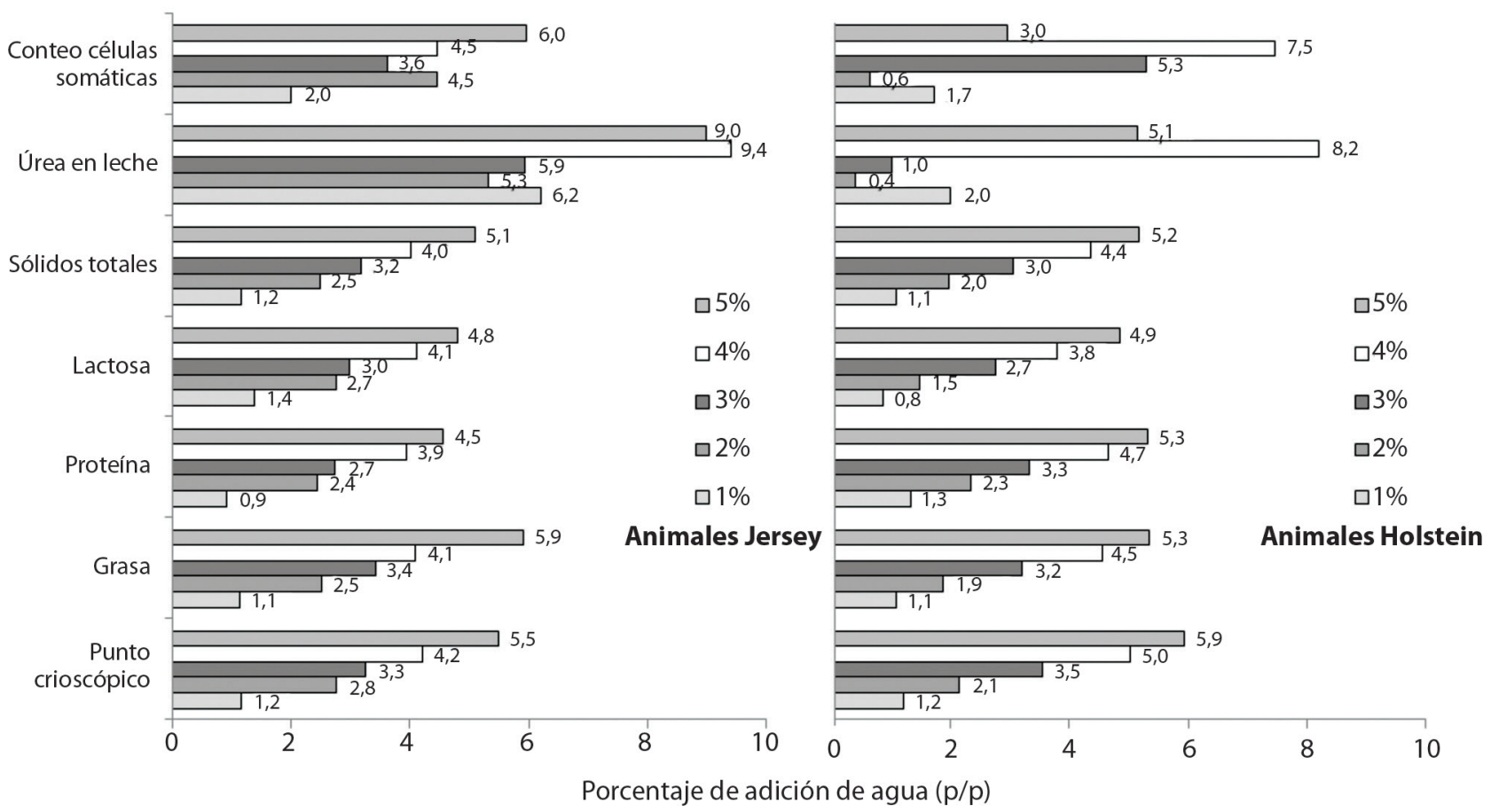

Fig. 2. Respuesta porcentual en los componentes de la leche cruda de animales Jersey y Holstein a adiciones crecientes de agua hasta $5 \%(p / p)$.

De igual manera en la segunda de esta prueba, al utilizar adulteraciones de 1, 2, 3, 4 y $5 \%$ de agua $(\mathrm{p} / \mathrm{p})$, la leche entera de estos animales en producción refleja cambios significativos $(p<0,05)$ en su punto crioscópico, contenidos bromatológicos y conteo de células somáticas debidas a la adición de $1 \%$ de agua en las muestras analizadas (Cuadro 2, Fig. 2).

En el caso de la urea en leche, en ambas razas se observa una capacidad amortiguadora de hasta $4 \%$ de adulteración con agua, para que se note un cambio significativo. En el caso del contenido de grasa, solo en las muestras de animales Jersey, se cuantifico un cambio significativo por encima de $2 \%(\mathrm{p} / \mathrm{p})$ de adicción de agua.
Al analizar la respuesta porcentual en los cambios por adulteración con agua, el punto crioscópico, el porcentaje de grasa, proteína, lactosa y sólidos totales de la leche, se nota un patrón similar a la cantidad adicionada, mientras que el valor de urea en leche y el conteo de células somáticas, no presenta una tendencia clara.

En el caso de las razas estudiadas, se nota que la raza Holstein presenta un valor mayor de punto crioscópico que los animales Jersey (Cuadro 3). De igual manera, el porcentaje de lactosa y los valores de urea en leche. En cambio, los porcentajes de grasa, proteína y sólidos totales favorecen a la raza Jersey sobre los animales Holstein analizados.

CUADRO 3

Contenido de grasa, proteína, lactosa, sólidos totales, urea y punto crioscópico de la leche entera cruda de animales Jersey y Holstein

\begin{tabular}{lccccc}
\multicolumn{1}{c}{ Variables } & Unidades & $\mathrm{N}^{\circ}$ & Holstein & Jersey & Pr $>\mathrm{F}$ \\
Punto crioscópico & $\mathrm{m}^{\circ}$ Horvert & 20 & 545,7 & 538,4 & $<0,0001$ \\
Grasa & $\%$ & 20 & 3,60 & 4,49 & $<0,0001$ \\
Proteína & $\%$ & 20 & 3,02 & 3,37 & $<0,0001$ \\
Lactosa & $\%$ & 20 & 4,73 & 4,54 & 0,0044 \\
Sólidos totales & $\%$ & 20 & 12,01 & 13,14 & $<0,0001$ \\
MUN & $\%$ & 20 & 14,38 & 11,56 & $<0,0001$ \\
\hline
\end{tabular}




\section{DISCUSIÓN}

La leche obtenida de los animales Holstein y Jersey en esta investigación presenta un contenido de agua de 87,99 y $86,86 \%$ respectivamente. La adición mínima de $1 \%$ de agua a un volumen conocido de leche cruda entera diluye los componentes de esta, lo que genera una disminución significativa en los valores promedio para cada raza evaluada. Comportamiento que permite establecer un valor de referencia para cada raza, por el cual, lecturas debajo del mismo, se asocian a adulteraciones con agua. La diferencia obtenida entre razas para el punto crioscópico puede relacionarse a factores ambientales, de manejo y de la raza (Henno et al., 2008). En el caso de la raza, esta se relaciona a la composición de la leche, donde el contenido de lactosa, sales de cloro y otros constituyentes solubles (calcio, magnesio y potasio) de la leche influyen en 55,25 y $20 \%$ en el punto crioscópico, respectivamente (Henno et al., 2008). De igual manera, otros autores indican que el contenido de lactosa influye en $53,2 \%$ el valor del punto crioscópico de la muestra de leche analizada (Senevirathne, Maugalika, Adikari, \& Nayananjalie, 2016). Mientras que, el contenido de potasio, cloro, sodio, citrato y urea se le atribuye un efecto a este punto de 12,$7 ; 10,5 ; 7,2 ; 4,3$ y $1,9 \%$ respectivamente (Zagorska \& Ciprovica, 2013).

Además de estos factores, la composición de la leche y por consiguiente el punto crioscópico es afectada por la ocurrencia de mastitis subclinica, consumo de agua, estrés calórico, presencia de $\mathrm{CO}_{2}$ en la leche (Janštová, Dračková, Navrátilová, Hadra, \& Vorlová, 2007) el periodo del año, condiciones ambientales, edad y tipo de alimentación del animal, periodo de lactancia, nivel de producción (Dabija, Mironeasa, Orojan, \& Sion, 2018) y el ciclo estral de la vaca (Toledo-Alvarado et al. 2018). En este trabajo, ambos sitios presentan condiciones climáticas diferentes, lo que propicia condiciones de estrés calórico en los animales Jersey (Conejo, 2017), que afectan el consumo de materia seca por consiguiente el aporte de nutrimentos para la producción de leche, lo cual, se asocia a los nutrimentos presentes en el torrente sanguíneo y los alveolos de la ubre, durante la síntesis de la leche (Strucken, Laurenson, \& Brockmann 2015). Argumento que se fortalece, al analizar el contenido de urea en leche presente en las muestras analizadas, donde se determina una diferencia de $2,82 \mathrm{mg} / \mathrm{dL}$ que favorece a los animales Holstein, valor asociado a una mayor cantidad de proteína degradable en la ración que reciben los animales durante el día y que indica que los animales Jersey, no alcanzan el rango óptimo de 12 a $16 \mathrm{mg} / \mathrm{dL}$ de urea en leche (Gonzáles \& WingChing-Jones, 2016).
En el caso de la grasa de la leche, la cual favorece en $0,89 \%$ a los animales Jersey, no se asocia como un agente modificador del punto crioscópico, comportamiento que relaciona al tamaño de la partícula y a la composición de la molécula de grasa, donde el 97 al 98\% de esta, es una mezcla de triacilgliceroles (acilgliceridos de tres moléculas de ácido graso) y de vitaminas liposolubles, ceras, esteroles, pigmentos y lípidos neutros (Gantner et al., 2015).

Al comparar ambas razas, es importante considerar que al transformar estos porcentajes a kilogramos de grasa, proteína, lactosa y sólidos totales, los animales Holstein (25L/animal/día) superan en 180 (900 contra $720 \mathrm{~g} / \mathrm{animal} / \mathrm{d}$ ), 210 (750 contra $540 \mathrm{~g} / \mathrm{animal} / \mathrm{d}), 460$ (1 180 contra $720 \mathrm{~g} /$ animal/d) y 900 (3.000 contra $2100 \mathrm{~g} /$ animal/d) g/animal/d a los animales Jersey (16L/ani$\mathrm{mal} / \mathrm{d}$ ) respectivamente, lo que genera un mayor ingreso por animal relacionado a la venta de la leche, sin considerar los gastos en que se incurre en el manejo nutricional, sanitario y vida productiva de cada semoviente.

En el caso de los conteos bacteriales y conteos de células somáticas, el comportamiento obtenido se asocia a una respuesta a la dilución de la muestra analizada por incrementar el volumen de agua. Pero en el caso de animales Holstein, relacionado al conteo bacterial de las muestras, se podría relacionar a un problema de contaminación no visible del agua utilizada para la adulteración, que afecto la tendencia obtenida en esta variable, que se obtuvo en las siete variables analizadas, la cual fue hacia la baja.

\section{AGRADECIMIENTOS}

Se agradece a la Unidad de Calidad de la Leche de la Cooperativa Productores de Leche Dos Pinos R.L y a los sistemas de producción que permitieron la toma de la muestra en los sistemas productivos.

\section{REFERENCIAS}

Albernethy, G. A., Bendall, J. G., \& Holroyd, S. E. (2016). Advances in testing for adulteration and authenticity of dairy products. In G. Downey (Ed.), Advances in food authenticity testing (pp. 461-490.) Cambridge, UK: Woodhead publishing, Elsevier. DOI: 10.1016/ B978-0-08-100220-9.00017-5

Alhussien, M. N., \& Dang, A. K. (2018). Milk somatic cells, factors influencing their release, future prospects, and practical utility in dairy animals: An overview, Veterinary World, 11(5), 562-577. DOI: 10.14202/vetworld.2018.562-577

Bohlouli, M., Alijani, S., \& Varposhti, M. (2015). Genetic relationships among linear type traits and milk production traits 
of Holstein Dairy cattle. Annals of Animal Science, 15(4), 903-917. DOI: 10.1515/aoas-2015-0053

Conejo, J. (2017). Efecto de las condiciones ambientales sobre la producción láctea de dos hatos de ganado Jersey en dos pisos altitudinales de la provincia de Cartago (Tesis de licenciatura). Universidad de Costa Rica, San José, Costa Rica.

Dabija, A., Mironeasa, S., Orojan, M., \& Sion, I. (2018). Study concerning milk quality-Raw material for dairy Industry. International Journal of Food Engineering, 4(1), 14-21. DOI: 10.18178/ijfe.4.1.14-21.

Depeters, E. J., Medrano, J. F., \& Reed, B. A. (1995) Fatty acid composition of milk fat from three breeds of dairy cattle. Canadian Journal of Animal Science, 75, 267269. DOI:10.4141/cjas95-040

Dos Pinos. (2016). Reglamento de recibo y recolección de leche 2015. Aprobado por el Consejo de Administración en la sesión N³401 del 10 de marzo 2015. Cooperativa de Productores de Leche Dos Pinos R.L., San José, Costa Rica, 24 pp.

Feltes, G., Michelottil, V., Prestes, A., Bravo, A., Bondan, C., Dornelles, M., Breda, F., \& Rorato, P. (2016). Milk production and percentages of fat and protein in Holstein breed cows raised in Rio Grande do Sul, Brazil. Ciência Rural, Santa Maria, 46(4), 700-706. DOI:10.1590/0103-8478cr20150465

Gantner, V., Mijić, P., Baban, M., Škrtić, Z., \& Turalija, A. (2015). The overall and fat composition of milk of various species. Mljekarstvo 65(4), 223-231. DOI: 10.15567/ mljekarstvo.2015.0401

Gao, X., \& Oba, M. (2016). Effect of increasing dietary nonfiber carbohydrate with starch, sucrose, or lactose on rumen fermentation and productivity of lactating dairy cows. Journal of Dairy Science, 99, 1-10 DOI: 10.3168/ jds.2015-9871

Gonzáles J., \& WingChing-Jones, R. (2016). Relación del valor de urea en leche con parámetros reproductivos y productivos en vacas Holstein, Jersey y sus cruces. UNED Research Journal, 8(2), 175-183. DOI: 10.22458/urj.v8i2.1558

Hanuš, O., Zhang, Y., Bjelka, M., Kučera, J., Roubal, P., \& Jedelská, R. (2011). Chosen biotic factors influencing raw cow milk freezing point. Acta Universitatis Agriculturae et Silviculturae Mendelianae Brunensis, 59(5), 65-82. DOI:10.11118/actaun201159050065

Henno, M., Ots, M., Joudu, I., Kaart, T., \& Kart, O. (2008). Factors affecting the freezing point stability of milk from individual cows. International Dairy Journal, 18, 210-215. DOI:10.1016/j.idairyj.2007.08.006

Iwaniuk, M., \& Erdman, R. (2015). Intake, milk production, ruminal, and feed efficiency responses to dietary cation-anion difference by lactating dairy cows. Journal of Dairy Science, 98, 1-13. DOI: 10.3168/jds.2015-9949

Janštová, B., Dračková, M., Navrátilová, P., Hadra, L., \& Vorlová, L. (2007). Freezing point of raw and heat-treated goat milk. Czech Journal of Animal Science, 52(11), 394-398. DOI: 10.17221/2324-CJAS

Juárez-Barrientos, J., Rodríguez-Miranda, J., Martínez-Sánchez, C., Hernández-Santos, B., Paz-Gamboa, E., GómezAldapa, C., Díaz-Rivera, P., \& Herman-Lara, E.. (2015). Evaluación y clasificación de calidad de leches comerciales consumidas en Tuxtepec, Oaxaca, México. Ecosistema y Recursos Pecuarios 2(6), 327-337.

Kedzierska-Matysek, M., Litwinczuk, Z., Florek, M., \& Balowska, J. (2011). The effects of breed and other factor son the composition and freezing point of cow's milk in Poland. International Journal of Dairy Technology, 64(3), 336-342. DOI:10.1111/j.1471-0307.2011.00682.x

Nascimento, W., Souza, M., Valente, A., Anjos, V., Furtado, M., \& Bell, M. (2017). Results from portable and low cost equipment developed for detection of milk adulterations. Food Science and Technology 37(Special issue), 38-41. DOI:10.1590/1678-457X.06617

Senevirathne, P., Mangalika U., Adikari, A., \& Nayananjalie, W. (2016). Evaluation of cow factors and milk composition on freezing point depression of cow milk. International Journal of Livestock Research, 6(5), 61-67. DOI:10.5455/ ijlr.20160512114121d

Sinclair, K. D., Garnsworthy, P. C., Mann, G. E., \& Sinclair, L. A.. (2014). Reducing dietary protein in dairy cow diets: implications for nitrogen utilization, milk production, welfare and fertility. Animal, 8(2), 262- 274. DOI: 10.1017/ S1751731113002139

Strucken, E., Laurenson, Y., \& Brockmann, G. (2015). Go with the flow-biology and genetics of the lactatation cycle. Review. Frontiers in Genetics, 6, 118. DOI: 10.3389/ fgene.2015.00118.

Toledo-Alvarado, H., Vazquez, A. I., de los Campos, G., Tempelman, R. J., Gabai, G., Cecchinato, A., \& Bittante, G. (2018). Changes in milk characteristics and fatty acid profile during the estrous cycle in dairy cows. Journal of Dairy Science, 101(10), 9135-9153. DOI:10.3168/ jds.2018-14480

Walstra, P; Wouters J., \& Geurts, T. (2006). Dairy Science and Technology (2 ed.). LLC, USA: Taylor \& Francis Group.

WingChing-Jones, R., \& Mora-Chaves, E. (2013). Composición de la leche entera cruda de bovinos antes y después del filtrado. Agronomía mesoamericana, 24(1), 203-207.

WingChing-Jones, R., \& Mora-Chaves, E. (2015). Condiciones ambientales y calidad de la leche cruda de un hato Jersey especializado en el trópico húmedo de Costa Rica. UNED Research Journal, 7(2), 165-171. DOI:10.15517/ am.v24i1.9799

Zagorska, J., \& Cirpovica, l. 2013. Evaluation of factors affecting freezing point of milk. International Journal of Nutrition and Food Engineering, 7(2), 106-111. Recuperado de www.scholar.waset.org/1307-6892/15910. 